\title{
Developing Common Set of Weights with Considering Nondiscretionary Inputs and Using Ideal Point Method
}

\author{
Reza Kiani Mavi, ${ }^{1}$ Sajad Kazemi, ${ }^{1}$ and Jay M. Jahangiri ${ }^{2}$ \\ ${ }^{1}$ Department of Industrial Management, Faculty of Management and Accounting, Islamic Azad University (IAU), \\ Qazvin Branch, Qazvin, Iran \\ ${ }^{2}$ Department of Mathematical Sciences, Kent State University, Burton, OH 44021-9500, USA
}

Correspondence should be addressed to Sajad Kazemi; s.kazemi_ie@yahoo.com

Received 22 August 2013; Accepted 3 November 2013

Academic Editor: Mark A. Petersen

Copyright (c) 2013 Reza Kiani Mavi et al. This is an open access article distributed under the Creative Commons Attribution License, which permits unrestricted use, distribution, and reproduction in any medium, provided the original work is properly cited.

\begin{abstract}
Data envelopment analysis (DEA) is used to evaluate the performance of decision making units (DMUs) with multiple inputs and outputs in a homogeneous group. In this way, the acquired relative efficiency score for each decision making unit lies between zero and one where a number of them may have an equal efficiency score of one. DEA successfully divides them into two categories of efficient DMUs and inefficient DMUs. A ranking for inefficient DMUs is given but DEA does not provide further information about the efficient DMUs. One of the popular methods for evaluating and ranking DMUs is the common set of weights (CSW) method. We generate a CSW model with considering nondiscretionary inputs that are beyond the control of DMUs and using ideal point method. The main idea of this approach is to minimize the distance between the evaluated decision making unit and the ideal decision making unit (ideal point). Using an empirical example we put our proposed model to test by applying it to the data of some 20 bank branches and rank their efficient units.
\end{abstract}

\section{Introduction}

Data envelopment analysis (DEA) which was first proposed by Charnes et al. [1] and developed by Banker et al. [2] is a nonparametric technique for measuring the efficiency of a homogeneous group of decision making units (DMUs) on the basis of multiple inputs and outputs based on observed data [3-7]. DEA provides weights that are DMU-specific and permits individual circumstances of operation of the DMUs and for each DMU, it provides efficiency scores in the form of a ratio of a weighted sum of the outputs to a weighted sum of the inputs [8].

This method was applied to evaluate productivity and performance of airports, efficiency of air force maintenance units, hospitals, university departments, schools, industries, banks, products and services, strategic decision making, and technologies [9].

On the basis of various assumptions, a number of different models have been developed. The DEA models may be generally classified into radial and nonradial models. The radial models include the $\mathrm{CCR}$ and the $\mathrm{BCC}$ models, and the nonradial models include the additive model, the multiplication model, the range-adjusted measure (RAM), and the slack-based measure (SBM) $[5,10,11]$.

Fundamental assumptions of the original DEA models [12] are that inputs and outputs are measured by exact values or are factual and definite factors [4] and assume that the assessed units (DMUs) are homogeneous. In other words, they perform the same tasks with similar objectives, consume similar inputs and similar outputs, and operate in similar operational environments and generally called discretionary factors [6]. However, in the real world situations and in many applications of the efficiency evaluation of the units, the assumption of homogeneous environments may be violated and the factors that describe the differences in the environments may need to be included in the analysis. These factors as well as other factors that are beyond the control of the DMU's management, frequently called "exogenously fixed" or nondiscretionary, also need to be considered. Some examples of nondiscretionary factors in the DEA literature are the 
number of competitors in a restaurant chain and snowfall or weather in evaluating the efficiency of maintenance units and so forth $[6,9,13]$.

The efficiency scores of decision making units, when DEA models are used, are between zero and one inclusively $[3,5]$. DEA successfully divides them into two categories: efficient DMUs and inefficient DMUs. A ranking for inefficient DMUs is given; however, efficient DMUs cannot be ranked [7]. In order to differentiate these efficient units, a variety of methods or "ranking efficient units" in the DEA are proposed [3]. For example, Anderson and Petersen [14] and Mehrabian et al. [15] introduced two of the most popular methods, namely, AP and MAJ. Cook et al. [16] divided efficient units with equal scores on the boundary, by imposing the restrictions on the weights in a DEA analysis. Jahanshahloo et al. [17] introduced L1-norm approach that removes some deficiencies arising from AP and MAJ but fails to rank nonextreme DMUs. Liu and Hsuan Peng [18] introduced a common set of weights (CSW) to create the best efficiency score of one group composed of efficient DMUs. They then used this common set of weights to evaluate the absolute efficiency of each efficient DMU in order to rank it $[5,7]$.

Here in this paper, we use a method to rank the efficiency of DMUs and obtain the common set of weights model, that is, extended with nondiscretionary inputs to evaluate the absolute efficient DMUs. Using this common set of weights, the efficiency scores for DMUs are also obtained. In Section 2, we propose our model according to the CCR model which was initially proposed by Charnes, Cooper, and Rhodes in 1978, and we briefly review a general CSW method while the CSW with ideal point method is described in Section 3. Nondiscretionary version of the DEA model is extended in Section 4. Section 5 includes the extended proposed mode and in Section 6, we apply the model in empirical example. Finally Section 7 includes the paper's conclusions and future research ideas.

\section{CCR Model}

Using the traditional denotations in DEA, we assume that there are a set of $n$ DMUs, and each $\operatorname{DMU}_{j}(j=1, \ldots$, $n$ ) produces $s$ different outputs using $m$ different inputs which are denoted by $x_{i j}(i=1, \ldots, m)$ and $y_{r j}(r=1, \ldots, s)$, respectively. Here $x_{i j}$ and $y_{r j}$ are all positive [1]. For any evaluated $\mathrm{DMU}_{j}$, the efficiency score $H$ can be calculated by the following CCR model according to following hypotheses:

$j$ is the number of decision making units (DMUs) being compared in the DEA analysis,

$\mathrm{DMU}_{j}$ the $j$ th decision making unit,

$\theta$ the efficiency rating of the decision making unit being evaluated by DEA,

$y_{r j}$ the amount of output $r$ used by decision making unit $j$, $x_{i j}$ the amount of input $i$ used by decision making unit $j$,

$i$ the number of inputs used by the DMUs,

$r$ the number of outputs generated by the DMUs,

$u_{r}$ the coefficient or weight assigned to output $r$ by DEA, and

$v_{i}$ the coefficient or weight assigned to input $i$ by DEA.

Also,

$$
\begin{array}{cc}
\operatorname{Max} & H=\sum_{r=1}^{s} u_{r} y_{r o}, \\
\text { subject to } \sum_{r=1}^{s} u_{r} y_{r j}-\sum_{i=1}^{m} v_{i} x_{i j} \leq 0, \quad j=1,2, \ldots, n, \\
\sum_{i=1}^{m} v_{i} x_{i o}=1, \quad u_{r} \geq 0, \quad v_{i} \geq 0, \\
r=1, \ldots, s, i=1, \ldots, m .
\end{array}
$$

And the dual of model (1) is

$$
\begin{array}{cc}
\text { Min } & D=\theta_{o} \\
\text { subject to } \quad \sum_{j=1}^{n} \lambda_{j} x_{i j} \leq \theta_{o} x_{i o}, \quad i=1, \ldots, m . \\
\sum_{j=1}^{n} \lambda_{j} y_{r j} \geq y_{i o}, \quad r=1, \ldots, s ; \\
\lambda_{j} \geq 0, \quad j=1,2, \ldots, n .
\end{array}
$$

A characteristic of the above DEA model can be used to evaluate the relative efficiency of its favorable weights in order to calculate its maximum efficiency score for each decision making unit. We note that these efficiency scores usually lie in $(0,1]$. The DEA successfully divides them into two categories: efficient DMUs and inefficient DMUs. A ranking for inefficient DMUs is given; however, DEA does not provide sufficient information about the efficient DMUs. It is noteworthy that one of the popular methods for evaluating and ranking DMUs is the common set of weights (CSW) method $[7,43]$.

\section{Common Set of Weights}

As the mathematical models in DEA are run separately for each DMU, the set of weights will be different for the various DMUs, and in some cases it is unacceptable that the same factor is accorded widely differing weights. This flexibility in selecting the weights deters the comparison among DMUs on a common base. A possible answer to this difficulty lies in the specification of a common set of weights, which was first introduced by Cook et al. [44] and Roll et al. [21] in the context of applying DEA to evaluate highway maintenance units. In other words, the major purpose for generating a common 
set of weights is to provide a common base for ranking the DMUs $[18,34]$.

It is argued by Kao and Hung [31] that using different sets of weights to classify the DMUs as efficient or inefficient is acceptable to the practitioners; however, if different sets of weights are used for ranking, most practitioners may not agree. To reduce the flexibility in selecting input and output weights, common weights have been suggested instead of variable weights for assessing the performances of DMUs. The use of common weights makes it possible to compare and rank the performances of the DMUs on the same basis [39].

Table 1 gives a brief summary of some relevant research on DEA to find CSW.

3.1. Common Set of Weights by Comparing with Ideal DMU (Ideal Point). DEA was initially developed as a methodology for assessing the comparative efficiencies of organized units. In conventional DEA models each DMU in turn maximizes the efficiency score, under the constraint that none of the DMUs efficiency scores is allowed to exceed 1.0. Decision maker always intuitively takes the maximal efficiency score 1.0 as the common benchmark level for DMUs. Liu and Hsuan Peng [18] have taken advantage of this benchmark level to concretely describe the concept of the generation of common weights. By the definition of the efficiency score, the common benchmark level is one straight line with slope 1.0 that passes through the origin. Some might argue that it cares too much about distance of each DMU's input and output itself and wonder why not consider the distance between the evaluated decision making unit and the ideal decision making unit. Here we attempt to rank efficiency of DMUs with common weights by comparison of ideal point (ideal DMU: $\overline{\mathrm{DMU}}$ ).

Definition 1. Assume that there are a set of $n$ DMUs. Each $\operatorname{DMU}_{j}(j=1, \ldots, n)$ has $m$ different inputs and $s$ different outputs, which are denoted by $x_{i j}(i=1,2, \ldots, m)$ and $y_{r j}(r=1,2, \ldots, s)$, respectively. All the data are required to be positive just like the traditional DEA model [1]. The input data of all DMUs form an $m$ by $n$ matrix and output data form an $s$ by $n$ matrix. The smallest data of each row of input matrix is selected to be the input of the virtual ideal DMU, and the biggest data of each row of output matrix is selected to be the output of the virtual ideal DMU.

The virtual ideal DMU is a DMU with minimized inputs of all of DMUs as its input and maximized outputs of all of DMUs as its output. Generally, if we show ideal DMU with $\overline{\mathrm{DMU}}=(\bar{X}, \bar{Y})$, then we have $\bar{x}_{i}=\min \left\{x_{i j} \mid j=1, \ldots, n\right\}(i=$ $1, \ldots, m)$ and $\bar{y}_{r}=\max \left\{y_{r j} \mid j=1, \ldots, n\right\}(r=1, \ldots, s)$.

Definition 2. An ideal level is one straight line that passes through the origin and ideal DMU with slope 1.0.

In Figure 1, the vertical and horizontal axes are set to be the weighted sum of $s$ outputs and the weighted sum of $m$ inputs, respectively. Line "ox" is an ideal line representing that all the points on the line must satisfy the constraint that the weighted sum of $s$ outputs equals the weighted sum

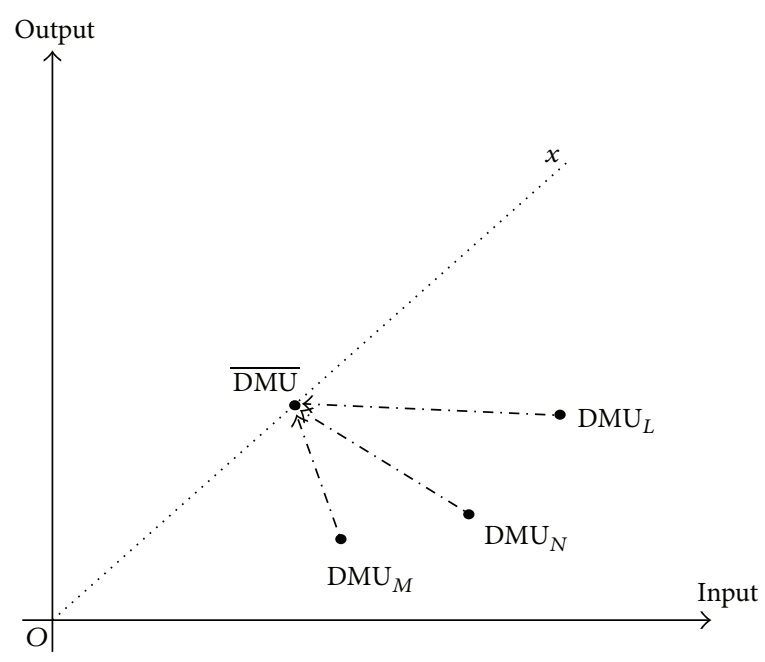

FIGURE 1: An illustration of the model for gap analysis, showing DMUs below the virtual ideal DMU.

of $m$ inputs and so $\overline{\mathrm{DMU}}=\left(\sum_{i=1}^{m} \bar{x}_{i} \hat{v}_{i}, \sum_{r=1}^{s} \bar{y}_{r} \dot{u}_{r}\right)$ is an ideal DMU. Given one set of weights $\dot{u}_{r}(r=1, \ldots, s)$ and $\hat{v}_{i}(i=1, \ldots, m)$, the virtual gaps, between points $M$ and $\overline{\mathrm{DMU}}$ on the horizontal axis and vertical axis, are denoted by $\Delta_{M}^{I}=\sum_{j=1}^{n} v_{M} x_{M j}-\sum_{j=1}^{n} v_{M} x_{\min }$ and $\Delta_{M}^{R}=\sum_{j=1}^{n} u_{M} y_{\max }-$ $\sum_{r=1}^{s} u_{M} y_{M j}$, respectively. Similarly, for points $N$ and $L$, the gaps will be calculated $\left(\Delta_{N}^{I}, \Delta_{N}^{R}\right.$ and $\left.\Delta_{L}^{I}, \Delta_{L}^{R}\right)$. Observing that there exists a total virtual gap to the ideal point, we aim to determine an optimal set of weights $u_{r}^{*}(r=1, \ldots, s)$ and $v_{i}^{*}(i=1, \ldots, m)$ such that both points $M^{*}$ and $N^{*}$ below the ideal line could be as possibly close to their ideal point ( $\overline{\mathrm{DMU}})$ on the ideal line. In other words, by adopting the optimal weights, the total virtual gaps $\Delta_{M}^{I}+\Delta_{M}^{R}+\Delta_{N}^{I}+\Delta_{N}^{R}+$ $\Delta_{L}^{I}+\Delta_{L}^{R}$ to the ideal point are the shortest to $\overline{\mathrm{DMU}}$.

As for the constraint, the numerator is the weighted sum of outputs plus the vertical gap $\sum_{j=1}^{n} \Delta_{j}^{I}$ and the denominator is the weighted sum of inputs minus the horizontal virtual gap $\sum_{j=1}^{n} \Delta_{j}^{R}$. The equations in constraints are equal to 1.0 , meaning that the projection point (ideal DMU) is reached. Therefore we have the following model:

$$
\begin{gathered}
\text { Min } \Delta^{*}=\sum_{j=1}^{n}\left(\Delta_{j}^{I}\right)+\sum_{j=1}^{m}\left(\Delta_{j}^{R}\right) \\
\text { subject to } \sum_{i=1}^{m} v_{i} x_{i j}-\sum_{r=1}^{s} u_{r} y_{r j} \geq 0, \quad j=1,2, \ldots, n \\
\sum_{i=1}^{m} v_{i} x_{\min }=1 ; \quad \sum_{r=1}^{s} u_{r} y_{\max }=1, \\
v_{i}, u_{r} \geq \varepsilon \geq 0, i=1, \ldots, m, \\
r=1, \ldots, s .
\end{gathered}
$$


TABLE 1

\begin{tabular}{|c|c|c|c|}
\hline Number & CSW methods developed & Authors & Year \\
\hline 1 & $\begin{array}{l}\text { Provided a subjective ordinal preference ranking by developing } \\
\text { common weights through a series of bounded DEA runs, by closing } \\
\text { the gap between the upper and lower limits of the weights. }\end{array}$ & Cook and Kress $[19,20]$ & $\begin{array}{c}1990 \\
1991\end{array}$ \\
\hline 2 & $\begin{array}{c}\text { Used a general unbounded DEA model to obtain different sets of } \\
\text { weights and then taking their average or weighted average with DEA } \\
\text { efficiencies as the weights, maximizing the average efficiency of } \\
\text { DMUs, maximizing the number of DEA efficient units, and ranking } \\
\text { various factors by some order of importance and then assigning low } \\
\text { weights to less important factors and maximal feasible weights to } \\
\text { important ones }\end{array}$ & $\begin{array}{l}\text { Roll et al. [21] } \\
\quad \text { Roll [22] }\end{array}$ & $\begin{array}{l}1991 \\
1993\end{array}$ \\
\hline 3 & $\begin{array}{c}\text { Considered the common weights for all the units, by maximizing the } \\
\text { sum of efficiency ratios of all the units, in order to rank each unit as } \\
\text { well as suggesting a potential use of the common weights for ranking } \\
\text { DMUs. }\end{array}$ & Ganley and Cubbin [23] & 1992 \\
\hline 4 & $\begin{array}{l}\text { Developed a two-stage linear discriminate analysis approach to } \\
\text { generate the common weights }\end{array}$ & Sinuany-Stern, et al. [24] & 1994 \\
\hline 5 & $\begin{array}{l}\text { Developed a maxi-min efficiency ratio model which also creates } \\
\text { common weights for evaluation }\end{array}$ & Troutt [25] & 1995 \\
\hline 6 & $\begin{array}{l}\text { Used the canonical correlation analysis to provide a single weight } \\
\text { vector for inputs and outputs, respectively, common to all DMUs. }\end{array}$ & $\begin{array}{l}\text { Friedman and Sinuany-Stern } \\
\qquad[26]\end{array}$ & 1997 \\
\hline 7 & $\begin{array}{l}\text { Presented a nonlinear discriminate analysis to provide the common } \\
\text { weights for all DMUs. }\end{array}$ & $\begin{array}{l}\text { Sinuany-Stern and Friedman } \\
{[27]}\end{array}$ & 1998 \\
\hline 8 & Presented the multiple objectives max-min model to determine CSW & Chiang and Tzeng [28] & 2000 \\
\hline 9 & $\begin{array}{l}\text { Minimizes a convex combination of these deviations measured in } \\
\text { terms of a couple of distances in such family }\end{array}$ & Despotis [29] & 2002 \\
\hline 10 & $\begin{array}{l}\text { Proposed a DEA-CP (compromise programming) model which aims } \\
\text { at seeking a common set of weights across the DMUs by combining } \\
\text { the DEA and the compromise programming. }\end{array}$ & Hashimoto and $\mathrm{Wu}[30]$ & 2004 \\
\hline
\end{tabular}

Based on multiple objective nonlinear programming and by using compromise solution approach, proposed a method to generate a

11 common set of weights for all DMUs which are able to produce a vector of efficiency scores closest to the efficiency scores calculated from the standard DEA model (ideal solution)

Based on multiple objective nonlinear programming and

12 maximization of the minimum value of the efficiency scores, proposed a method to generate a common set of weights for all

DMUs.

Developed a goal-programming model for this setting that seeks to derive such a common-multiplier set. The important feature of this multiplier set is that it minimizes the maximum discrepancy among the within-group scores from their ideal levels. And deal with these distances but relax the objective to groups of DMUs which operate in similar circumstances

\begin{tabular}{cccc}
\hline 14 & $\begin{array}{c}\text { Used a multiple objective linear programming (MOLP) approach for } \\
\text { generating a common set of weights in the DEA framework. }\end{array}$ & Makui et al. [34] \\
\hline 15 & $\begin{array}{c}\text { Proposed a common weights analysis (CWA) methodology to search } \\
\text { for a common set of weights for DMUs. }\end{array}$ & Liu and Peng [18] \\
\hline 16 & $\begin{array}{c}\text { Dealt with deviations regarding the total input virtual and the total } \\
\text { output virtual }\end{array}$ & Franklin Liu and Peng [35] \\
\hline
\end{tabular}

Introduced a minimum weight restriction and as a side effect, common weights are also achieved. Imposed weight restrictions to a full ranking, they are not explicitly discussed here. 
TABLe 1: Continued.

\begin{tabular}{|c|c|c|c|}
\hline Number & CSW methods developed & Authors & Year \\
\hline 18 & $\begin{array}{l}\text { Proposed two approaches to obtain the set of common weights for } \\
\text { ranking efficient DMUs by comparing with an ideal line and the } \\
\text { special line. }\end{array}$ & Jahanshahloo et al. [6] & 2010 \\
\hline 19 & $\begin{array}{l}\text { Proposed a CSW as the average of the profiles of weights provided by } \\
\text { the so-called "neutral" model used in the cross-efficiency evaluation. }\end{array}$ & Wang and Chin [37] & 2010 \\
\hline 20 & $\begin{array}{l}\text { Proposed a common weight MCDA-DEA method with a more } \\
\text { discriminating power over the existing ones that enable us to } \\
\text { construct CIs using a set of common weights. }\end{array}$ & Hatefi and Torabi [38] & 2010 \\
\hline 21 & $\begin{array}{l}\text { Used methods based on regression analysis to seek a common set of } \\
\text { weights that are easy to estimate and can produce a full ranking for } \\
\text { DMUs. }\end{array}$ & Wang et al. [39] & 2011 \\
\hline 22 & $\begin{array}{l}\text { A separation method is proposed for locating a set of weights, also } \\
\text { known as a common set of weights (CSW), in the data envelopment } \\
\text { analysis (DEA). }\end{array}$ & Chiang et al. [40] & 2011 \\
\hline 23 & $\begin{array}{l}\text { Extended a common-weights DEA approach involving a linear } \\
\text { programming problem to gauge the efficiency of the DMUs with } \\
\text { respect to the multiobjective model. }\end{array}$ & Davoodi and Rezai. [41] & 2012 \\
\hline 24 & $\begin{array}{l}\text { Used an approach to minimize the deviations of the CSW from the } \\
\text { DEA profiles of weights without zeros of the efficient DMUs. This } \\
\text { minimization reduces, in particular, the differences between the DEA } \\
\text { profiles of weights that are chosen, so the CSW proposed is a } \\
\text { representative summary of such DEA weights profiles. Several norms } \\
\text { to the measurement of such differences are used. }\end{array}$ & Ramón et al. [8] & 2012 \\
\hline 25 & $\begin{array}{l}\text { Proposed two models considering ideal and anti-ideal DMU to } \\
\text { generate common weights from the view of multiple criteria decision } \\
\text { analysis (MADA), for performance evaluation and ranking. }\end{array}$ & Sun et al. [42] & 2013 \\
\hline
\end{tabular}

Then, if we let $\Delta_{j}^{I}$ be $\sum_{i=1}^{m} v_{i} x_{i j}-\sum_{i=1}^{m} v_{i} x_{\min }$ and let $\Delta_{j}^{R}$ be $\sum_{r=1}^{s} u_{r} y_{\max }-\sum_{r=1}^{s} u_{r} y_{r j}$, model (3) is then simplified to the following linear programming (4):

Min

$$
\begin{aligned}
\Delta^{*}= & \sum_{j=1}^{n}\left(\sum_{i=1}^{m} v_{i} x_{i j}-\sum_{i=1}^{m} v_{i} x_{\min }\right) \\
& +\sum_{j=1}^{n}\left(\sum_{r=1}^{s} u_{r} y_{\max }-\sum_{r=1}^{s} u_{r} y_{r j}\right),
\end{aligned}
$$

subject to $\sum_{i=1}^{m} v_{i} x_{i j}-\sum_{r=1}^{s} u_{r} y_{r j} \geq 0, \quad j=1,2, \ldots, n$,

$$
\begin{array}{r}
\sum_{i=1}^{m} v_{i} x_{\min }=1 ; \quad \sum_{r=1}^{s} u_{r} y_{\max }=1, \\
v_{i}, u_{r} \geq \varepsilon \geq 0, \quad i=1, \ldots, m, \\
r=1, \ldots, s .
\end{array}
$$

Definition 3. The performance of $\mathrm{DMU}_{j}$ is better than that of $\mathrm{DMU}_{j}$ if $\Delta_{j}<\Delta_{i}$.
From the model (4), it is found that the distance between $\overline{\mathrm{DMU}}$ and $\mathrm{DMU}_{j}$ is defined as $\Delta_{j}^{I \mathrm{DMU}}=\left(\sum_{i=1}^{m} v_{i} x_{i j}-\right.$ $\left.\sum_{i=1}^{m} v_{i} x_{\text {min }}\right)+\left(\sum_{r=1}^{s} u_{r} y_{\max }-\sum_{r=1}^{s} u_{r} y_{r j}\right)$. Note that the purpose of the model (4) is to obtain an optimal solution $\left(v_{i}^{*}, u_{r}^{*}\right)$ to make the total distances between all DMUs and $\overline{\mathrm{DMU}}$ as short as possible $[6,42]$.

Next we find efficiency of each DMU with optimal weights. If a $\mathrm{DMU}_{j}$ is on ideal point then we use definition of the CSW efficiency score of $\mathrm{DMU}_{j}$ that was defined by the following equation (e.g., see $[18,45]$ ):

$$
\mu_{j}^{*}=\frac{\sum_{r=1}^{s} y_{r j} u_{r}^{*}-\sum_{i=1}^{n} z_{i j} \hat{v}_{i}^{*}}{\sum_{i=1}^{n} x_{i j} v_{i}^{*}} .
$$

\section{Nondiscretionary Model}

Assume that there are $n$ DMUs, where each $\mathrm{DMU}_{j}(j=$ $1,2, \ldots, n)$, uses $t$ different discretionary inputs, $x_{i j}(i=$ $1, \ldots, t)$, and $k$ different nondiscretionary inputs, $z_{i j}(i=$ $1, \ldots, k)$ for $t+k=m$, to produce $s$ different outputs $y_{r j}(r=$ $1, \ldots, s)$.

There are some models that incorporate nondiscretionary inputs into DEA models. Banker and Morey [45] provided the first model by modifying the constraints on the fixed factors within the DEA model. This model differs from the original 
CCR DEA model by breaking the link between nondiscretionary inputs and efficiency:

$$
\begin{gathered}
\operatorname{Max} \omega=\sum_{r=1}^{s} u_{r} y_{r o}-\sum_{i=1}^{k} v_{i} z_{i o} \\
\text { subject to } \sum_{r=1}^{s} u_{r} y_{r j}-\sum_{i=1}^{k} v_{i} z_{i j}-\sum_{i=1}^{t} v_{i} x_{i j} \leq 0, \\
j=1,2, \ldots, n, \\
\sum_{i=1}^{t} v_{i} x_{i o}=1, \quad v_{i} \geq \varepsilon, \quad i=1,2, \ldots, t, \\
u_{r} \geq \varepsilon, \quad r=1,2, \ldots, s, \\
v_{i} \geq 0, \quad i=1,2, \ldots, k .
\end{gathered}
$$

We note that there is a great similarity between fixed factor constraints and constraints on the nondiscretionary inputs while both constraints are modified. This modification is used to take the fixed factors of production under control in order to break the link between the efficiency and the fixed factors $[7,46]$.

Although this model allows each DMU to measure the efficiency with its favorable weights, to calculate its efficiency it may not be compared and ranked on the same basis. Moreover, some of the efficient DMUs may have their efficiency scores equal to one because of the flexibility in the selection of weights.

\section{Proposed Model}

To address the problems mentioned above, using ideal point (ideal DMU) method, we propose a new model to extend the existing nondiscretionary DEA model for generating common weights. This model allows us to obtain and compare the efficiency scores from multiple different angles.

Assume that there are $n$ DMUs, where each $\mathrm{DMU}_{j}(j=$ $1,2, \ldots, n)$ uses $t$ different discretionary inputs, $x_{i j}(i=$ $1, \ldots, t)$ and $k$ different nondiscretionary inputs, $z_{i j}(i=$ $1, \ldots, k)$ for $t+k=m$, to produce $s$ different outputs $y_{r j}(r=$ $1, \ldots, s)$.

Definition 1. The virtual ideal DMU is a DMU with minimized inputs of all of the DMUs as its input and maximized outputs of all of the DMUs as its output. Generally, if we show ideal DMU with $\overline{\mathrm{DMU}}=(\bar{X}, \bar{Y})$ then we have $\bar{x}_{i}=$ $\min \left\{x_{i j} \mid j=1, \ldots, n\right\}(i=1, \ldots, m)$ and $\bar{y}_{r}=$ $\max \left\{y_{r j} \mid j=1, \ldots, n\right\}(r=1, \ldots, s)$. Here $\bar{X}$ consists of two parts, comprehensive minimum discretionary and nondiscretionary inputs and one maximum output for ideal DMU.

For this reason, we have $\overline{\mathrm{DMU}}=(\bar{X}, \bar{Y})$ that $\bar{x}_{i 1}=$ $\min \left\{x_{i j}, \mid j=1, \ldots, n\right\}(i=1, \ldots, m), \bar{x}_{i 2}=\min \left\{z_{i j}, \mid j=1\right.$, $\ldots, n\}(i=1, \ldots, m)$, and $\bar{y}_{r}=\max \left\{y_{r j} \mid j=1, \ldots, n\right\}(r=$ $1, \ldots, s)$.
Then, according to models (4) and (6) we can construct the following model

Min

$$
\begin{aligned}
E= & \sum_{j=1}^{n}\left[\sum_{i=1}^{m} v_{i} x_{i j}-\sum_{i=1}^{m} v_{i} \bar{x}_{1 \min }\right] \\
& +\sum_{j=1}^{n}\left[\sum_{i=1}^{m} v_{i} z_{i j}-\sum_{i=1}^{m} \hat{v}_{i} \bar{x}_{2 \min }\right] \\
& +\sum_{j=1}^{n}\left[\sum_{r=1}^{s} u_{r} \bar{y}_{\max }-\sum_{r=1}^{s} u_{r} y_{r j}\right]
\end{aligned}
$$

subject to $\sum_{i=1}^{m} v_{i} x_{i j}+\sum_{i=1}^{m} v_{i} z_{i j}-\sum_{r=1}^{s} u_{r} y_{r j} \geq 0$

$$
j=1,2, \ldots, n,
$$

$$
\begin{aligned}
& \sum_{i=1}^{m} v_{i} \bar{x}_{1 \min }=1, \sum_{r=1}^{s} u_{r} \bar{y}_{\max }-\sum_{i=1}^{m} \hat{v}_{i} \bar{x}_{2 \min }=1, \\
& v_{i}, u_{r}, \hat{v}_{i} \geq \varepsilon>0, \quad i=1, \ldots, m, \quad r=1, \ldots, s .
\end{aligned}
$$

The dual of model (7) is

$\operatorname{Max}$

$$
T=\alpha+\beta+\varepsilon \sum_{i=1}^{m} \gamma_{i}+\varepsilon \sum_{i=1}^{m} \widetilde{\gamma}_{i}+\varepsilon \sum_{r=1}^{s} \delta_{r}
$$

subject to $\sum_{j=1}^{n} \lambda_{j} x_{i j}+\alpha \bar{x}_{1 \min }+\gamma_{i} \leq n\left(\sum_{i=1}^{m} x_{i j}-\bar{x}_{1 \mathrm{~min}}\right)$,

$$
i=1,2, \ldots, t .
$$

$$
\begin{array}{r}
\sum_{j=1}^{n} \lambda_{j} z_{i j}-\beta \bar{x}_{2 \min }+\widetilde{\gamma}_{i} \leq n\left(\sum_{i=1}^{m} z_{i j}-\bar{x}_{2 \min }\right), \\
i=1,2, \ldots, t . \\
\beta \bar{y}_{\max }-\sum_{j=1}^{n} \lambda_{j} y_{r j}+\delta_{r} \leq n\left(\bar{y}_{\max }-\sum_{r=1}^{s} y_{r j}\right), \\
r=1,2, \ldots, s, \lambda_{j}, \gamma_{i}, \tilde{\gamma}_{i}, \delta_{r} \geq 0, j=1,2, \ldots, n, \\
i=1,2, \ldots, m, r=1,2, \ldots, s, \alpha, \beta \rightarrow \text { free. }
\end{array}
$$

\section{Numerical Examples}

In this section we provide an empirical study of bank performance evaluation in order to demonstrate the robustness of our method as well as having a better understanding of the performance of our proposed model.

6.1. Empirical Example. To illustrate the proposed model consider 20 bank branches in Iran with 2 discretionary inputs and 1 nondiscretionary input and 2 outputs. In Tables 2, 3, 4, and 5, we apply models (6) and (7) to evaluate efficient DMUs. 
TABLE 2: Labels of inputs and outputs.

\begin{tabular}{lccc}
\hline Inputs & Description & Outputs & Description \\
\hline$X 1$ & The number of personnel & $Y 1$ & The number of insurance policies \\
$X 2$ & The total number of computers & $Y 2$ & The received total sum (income) \\
$Z 1$ & Distance of each branch to city centre & & \\
\hline
\end{tabular}

TABLE 3: The data of 20 bank branches.

\begin{tabular}{|c|c|c|c|c|c|}
\hline \multirow{2}{*}{ DMUs } & \multicolumn{2}{|c|}{ Discretionary inputs } & \multirow{2}{*}{$\begin{array}{l}\text { Nondiscretionary inputs } \\
\qquad 11 \\
\end{array}$} & \multicolumn{2}{|c|}{ Outputs } \\
\hline & $X 1$ & $X 2$ & & $Y 1$ & $Y 2$ \\
\hline 1 & 96 & 86 & 64 & 30 & 145 \\
\hline 2 & 75 & 88 & 1.2 & 0.001 & 175 \\
\hline 3 & 77 & 85 & 0.4 & 11 & 113 \\
\hline 4 & 91 & 93 & 2.3 & 10 & 128 \\
\hline 5 & 89 & 83 & 68 & 9 & 101 \\
\hline 6 & 102 & 97 & 0.8 & 7 & 82 \\
\hline 7 & 96 & 90 & 6.5 & 47 & 154 \\
\hline 8 & 85 & 92 & 2.3 & 11 & 54 \\
\hline 9 & 106 & 84 & 20.1 & 43 & 179 \\
\hline 10 & 107 & 95 & 1.4 & 9 & 117 \\
\hline 11 & 94 & 78 & 49 & 81 & 37 \\
\hline 12 & 78 & 89 & 1.7 & 11 & 124 \\
\hline 13 & 102 & 107 & 0.7 & 30 & 185 \\
\hline 14 & 82 & 92 & 1.4 & 28 & 51 \\
\hline 15 & 77 & 92 & 1.7 & 6 & 28 \\
\hline 16 & 89 & 85 & 23.5 & 15 & 85 \\
\hline 17 & 84 & 104 & 5.4 & 15 & 109 \\
\hline 18 & 94 & 91 & 1.9 & 13 & 72 \\
\hline 19 & 97 & 95 & 3.5 & 13 & 129 \\
\hline 20 & 82 & 100 & 1.2 & 29 & 150 \\
\hline
\end{tabular}

TABLE 4: The results of 20 bank branches from models (5)-(7).

\begin{tabular}{lccccccccc}
\hline DMUs & Model (6) & Rank & Models (5) and (7) & Rank & DMUs & Model (6) & Rank & Models (5) and (7) & Rank \\
\hline 1 & 0.8193072 & 7 & 0.814882 & 5 & 11 & 1.0000000 & 1 & 0.274558 \\
2 & 1.0000000 & 1 & 1.000001 & 2 & 12 & 0.7129804 & 9 & 0.703550 \\
3 & 0.6949586 & 11 & 0.667146 & 9 & 13 & 0.9295474 & 6 & 0.864070 \\
4 & 0.6982259 & 10 & 0.677215 & 8 & 14 & 0.7662059 & 8 & 0.293495 & 18 \\
5 & 0.5892561 & 13 & 0.586333 & 11 & 15 & 0.1801541 & 20 & 0.157402 \\
6 & 0.4343827 & 16 & 0.409140 & 15 & 16 & 0.4927510 & 15 & 0.489511 \\
7 & 1.0000000 & 1 & 0.845831 & 4 & 17 & 0.5596400 & 14 & 0.541312 \\
8 & 0.3169876 & 18 & 0.296808 & 17 & 18 & 0.4135209 & 17 & 14 \\
9 & 1.0000000 & 1 & 1.000017 & 1 & 19 & 0.2405702 & 19 & 0.388773 \\
10 & 0.6294556 & 12 & 0.585199 & 12 & 20 & 1.0000000 & 1 & 0.663105 \\
\hline
\end{tabular}

TABLE 5: The weights of model (6).

\begin{tabular}{lcccrr}
\hline Weights & Model (7) & Weights & Model (7) & Weights & Model (7) \\
\hline$v_{1}^{*}$ & $0.3080772 E-02$ & $\hat{v}_{1}^{*}$ & $0.1000000 E-05$ & $u_{1}^{*}$ & $0.7204692 E-03$ \\
$v_{2}^{*}$ & $0.9858232 E-02$ & & & $u_{2}^{*}$ & $0.6277616 E-02$ \\
\hline
\end{tabular}


The second, third, seventh, and eighth columns of Table 4 report the model (6) efficiency scores with nondiscretionary inputs and its rankings, respectively. This model allows DMUs to measure their efficiencies with various weights. Thus, the efficiencies of 20 DMUs obtained by 20 sets of weights may not be possible to be compared and ranked on the same basis, and so a common set of weights method in model (7) is utilized. The efficiencies of the 20 bank branches of model (7) with optimal weights and using (5) are shown in the fourth, fifth, ninth, and tenth columns of Table 4, respectively. Table 5 shows the weight results of the proposed model. It is evident that the new models can all be used for generating common weights. We emphasize that they all offer more reasonable results than the conventional DEA models.

Table 4 shows the efficiencies of all bank branches from two models. The column of model (6) gives the CCR efficiency scores with nondiscretionary inputs. Observe that there are 5 efficient DMUs with different selection weights. It is not possible to give them a full ranking.

In order to solve this problem, we propose a common set of weights model considering nondiscretionary inputs to calculate a set of optimal weights (see Table 5) for all DMUs. Using these and (5), all efficiency scores for all DMUs are calculated and ranked. The results are shown in the fourth, fifth, ninth, and tenth columns of Table 4.

Using models (7) and (5), clearly we can find an optimal set of weights for evaluating each DMU and calculate efficiency scores to rank all the bank branches completely which is preferable to that of using model (6).

The above empirical example shows that the new proposed DEA model can successfully acquire a full ranking for the DMUs. This method may be a good way for full ranking DMUs with various data since they are accustomed to a good unit of comparison.

\section{Conclusions and Future Research}

General DEA models are used to evaluate the relative efficiency with its favorable weights in order to calculate the efficiency score of each decision making unit. These obtained scores are between zero and one, with a possibility of some having an equal efficiency score of one (efficient DMUs) which is due to the flexibility in the selection of weights. DEA successfully divides DMUs into two categories: efficient DMUs and inefficient DMUs. Ranking of DMUs in DEA is an important phase for efficiency evaluation of DMUs. In DEA techniques, a ranking for inefficient DMUs is given. However, generally, DEA does not provide adequate information about the efficient DMUs and does not rank them.

One of the popular methods for evaluating and ranking efficiency and inefficiency DMUs is common set of weights (CSW) method, that is, the most favorable in determining the absolute efficiency for all of DMUs.

The conventional DEA methodology requires the inputs and the outputs of the DMUs to be discretionary. Nevertheless, in reality, many observations are nondiscretionary in nature. We generated a nondiscretionary version of a CSW model, that is, beyond the control of DMUs, and for this purpose we used ideal point method. The idea of this approach is to minimize the distance between the evaluated decision making unit and the ideal decision making unit (ideal point). Ranking DMUs determines the input and output weights by minimizing the distance of all DMUs and the point (ideal $\mathrm{DMU}$ ) to get the best efficiency score. The optimal solution of this model was considered as a set of weights for all DMUs. Then DMUs were ranked according to (5). To validate our model, we used an empirical example in ranking DMUs using our proposed model.

We hope that this paper will inspire future researchers to explore relevant ideas in developing CSW method to consider various data such as nondiscretionary inputs and stochastic data.

\section{References}

[1] A. Charnes, W. W. Cooper, and E. Rhodes, "Measuring the efficiency of decision making units," European Journal of Operational Research, vol. 2, no. 6, pp. 429-444, 1978.

[2] R. D. Banker, A. Charnes, and W. W. Cooper, "Some models for estimating technical and scale inefficiencies in data envelopment analysis," Management Science, vol. 30, no. 9, pp. 1078$1092,1984$.

[3] G. R. Jahanshahloo, F. Hosseinzadeh Lotfi, M. Sanei, and M. Fallah Jelodar, "Review of ranking models in data envelopment analysis," Applied Mathematical Sciences, vol. 2, no. 29-32, pp. 1431-1448, 2008.

[4] D. K. Despotis and Y. G. Smirlis, "Data envelopment analysis with imprecise data," European Journal of Operational Research, vol. 140, no. 1, pp. 24-36, 2002.

[5] V. Rezaie, G. R. Jahanshahloo, F. H. Lotfi, and M. Khanmohammadi, "Ranking DMUs by ideal points in DEA," International Journal of Mathematical Analysis, vol. 3, no. 17-20, pp. 919-929, 2009.

[6] G. R. Jahanshahloo, F. H. Lotfi, N. Shoja, A. G. Abri, M. F. Jelodar, and K. J. Firouzabadi, "Proposing a new model on data envelopment analysis by considering non discretionary factors and a review on previous models," Mathematical and Computational Applications, vol. 15, no. 3, pp. 344-353, 2010.

[7] G. R. Jahanshahloo, F. Hosseinzadeh Lotfi, M. Khanmohammadi, M. Kazemimanesh, and V. Rezaie, "Ranking of units by positive ideal DMU with common weights," Expert Systems with Applications, vol. 37, no. 12, pp. 7483-7488, 2010.

[8] N. Ramón, J. L. Ruiz, and I. Sirvent, "Common sets of weights as summaries of DEA profiles of weights: with an application to the ranking of professional tennis players," Expert Systems with Applications, vol. 39, no. 5, pp. 4882-4889, 2012.

[9] G. R. Jahanshahloo and S. Abbasian-Naghneh, "Data envelopment analysis with imprecise data," Applied Mathematical Sciences, vol. 5, no. 61-64, pp. 3089-3106, 2011.

[10] K. Tone, "A slacks-based measure of efficiency in data envelopment analysis," European Journal of Operational Research, vol. 130, no. 3, pp. 498-509, 2001.

[11] W. W. Cooper, K. S. Park, and J. T. Pastor, "RAM: A Range Adjusted Measure of inefficiency for use with additive models, and relations to other models and measures in DEA," Journal of Productivity Analysis, vol. 11, no. 1, pp. 5-42, 1999.

[12] A. Charnes, W. W. Cooper, A. Y. Lewin, and L. M. Seiford, Data Envelopment Analysis: Theory, Methodology and Applications, Kluwer Academic, Norwell, Mass, USA, 1994. 
[13] F. H. Lotfi, G. R. Jahanshahloo, and M. Esmaeili, "Nondiscretionary factors and imprecise data in DEA," International Journal of Mathematical Analysis, vol. 1, no. 5-8, pp. 237-246, 2007.

[14] P. Anderson and N. C. Petersen, "A procedure for ranking efficient units in data envelopment analysis," Management Science, vol. 39, no. 10, pp. 1261-1264, 1993.

[15] S. Mehrabian, M. R. Alirezaee, and G. R. Jahanshahloo, "A complete efficiency ranking of decision making units in data envelopment analysis," Computational Optimization and Applications, vol. 14, no. 2, pp. 261-266, 1999.

[16] W. D. Cook, M. Kress, and L. M. Seiford, "Prioritization models for frontier decision making units in DEA," European Journal of Operational Research, vol. 59, no. 2, pp. 319-323, 1992.

[17] G. R. Jahanshahloo, H. V. Junior, F. H. Lotfi, and D. Akbarian, "A new DEA ranking system based on changing the reference set," European Journal of Operational Research, vol. 181, no. 1, pp. 331-337, 2007.

[18] F.-H. F. Liu and H. Hsuan Peng, "Ranking of units on the DEA frontier with common weights," Computers and Operations Research, vol. 35, no. 5, pp. 1624-1637, 2008.

[19] W. D. Cook and M. Kress, "A multiple criteria decision model with ordinal preference data," European Journal of Operational Research, vol. 54, no. 2, pp. 191-198, 1991.

[20] W. D. Cook and M. Kress, "Data envelopment model for aggregating preference ranking," Management Science, vol. 36, no. 11, pp. 1302-1310, 1990.

[21] Y. Roll, W. D. Cook, and B. Golany, "Controlling factor weights in data envelopment analysis," IIE Transactions, vol. 23, no. 1, pp. 2-9, 1991.

[22] Y. Roll, "Alternate methods of treating factor weights in DEA," Omega, vol. 21, no. 1, pp. 99-109, 1993.

[23] J. A. Ganley and S. A. Cubbin, Public Sector Efficiency Measurement: Applications of Data Envelopment Analysis, NorthHolland, Amsterdam, The Netherlands, 1992.

[24] Z. Sinuany-Stern, A. Mehrez, and A. Barboy, "Academic departments efficiency via DEA," Computers and Operations Research, vol. 21, no. 5, pp. 543-556, 1994.

[25] M. D. Troutt, "A maximum decisional efficiency estimation principle," Management Science, vol. 41, no. 1, pp. 76-82, 1995.

[26] L. Friedman and Z. Sinuany-Stern, "Scaling units via the canonical correlation analysis in the DEA context," European Journal of Operational Research, vol. 100, no. 3, pp. 629-637, 1997.

[27] Z. Sinuany-Stern and L. Friedman, "DEA and the discriminant analysis of ratios for ranking units," European Journal of Operational Research, vol. 111, no. 3, pp. 470-478, 1998.

[28] C. I. Chiang and G. H. Tzeng, "A new efficiency measure for DEA: efficiency achievement measure established on fuzzy multiple objectives programming," Journal of Management, vol. 17, no. 2, pp. 369-388, 2000.

[29] D. K. Despotis, "Improving the discriminating power of DEA: focus on globally efficient units," Journal of the Operational Research Society, vol. 53, no. 3, pp. 314-323, 2002.

[30] A. Hashimoto and D.-A. Wu, "A DEA-compromise programming model for comprehensive ranking," Journal of the Operations Research Society of Japan, vol. 47, no. 2, pp. 73-81, 2004.

[31] C. Kao and H.-T. Hung, "Data envelopment analysis with common weights: the compromise solution approach," Journal of the Operational Research Society, vol. 56, no. 10, pp. 1196-1203, 2005.
[32] G. R. Jahanshahloo, A. Memariani, F. H. Lotfi, and H. Z. Rezai, "A note on some of DEA models and finding efficiency and complete ranking using common set of weights," Applied Mathematics and Computation, vol. 166, no. 2, pp. 265-281, 2005.

[33] W. D. Cook and J. Zhu, "Within-group common weights in DEA: an analysis of power plant efficiency," European Journal of Operational Research, vol. 178, no. 1, pp. 207-216, 2007.

[34] A. Makui, A. Alinezhad, R. Kiani Mavi, and M. Zohrehbandian, "A goal programming method for finding common weights in DEA with an improved discriminating power for efficiency," Journal of Industrial and Systems Engineering, vol. 1, no. 4, pp. 293-303, 2008.

[35] F.-H. Franklin Liu and H. H. Peng, "A systematic procedure to obtain a preferable and robust ranking of units," Computers and Operations Research, vol. 36, no. 4, pp. 1012-1025, 2009.

[36] Y.-M. Wang, Y. Luo, and L. Liang, "Ranking decision making units by imposing a minimum weight restriction in the data envelopment analysis," Journal of Computational and Applied Mathematics, vol. 223, no. 1, pp. 469-484, 2009.

[37] Y.-M. Wang and K.-S. Chin, "A neutral DEA model for crossefficiency evaluation and its extension," Expert Systems with Applications, vol. 37, no. 5, pp. 3666-3675, 2010.

[38] S. M. Hatefi and S. A. Torabi, "A common weight MCDADEA approach to construct composite indicators," Ecological Economics, vol. 70, no. 1, pp. 114-120, 2010.

[39] Y.-M. Wang, Y. Luo, and Y.-X. Lan, "Common weights for fully ranking decision making units by regression analysis," Expert Systems with Applications, vol. 38, no. 8, pp. 9122-9128, 2011.

[40] C. I. Chiang, M. J. Hwang, and Y. H. Liu, "Determining a common set of weights in a DEA problem using a separation vector," Mathematical and Computer Modelling, vol. 54, no. 910, pp. 2464-2470, 2011.

[41] A. Davoodi and H. Z. Rezai, "Common set of weights in data envelopment analysis: a linear programming problem," Central European Journal of Operations Research (CEJOR), vol. 20, no. 2, pp. 355-365, 2012.

[42] J. Sun, J. Wu, and D. Guo, "Performance ranking of units considering ideal and anti-ideal DMU with common weights," Applied Mathematical Modelling, vol. 37, no. 9, pp. 6301-6310, 2013.

[43] K. Cullinane and T. Wang -F, "Data envelopment analysis (DEA) and improving container port efficiency," in Devolution, Port Governance and Port Performance Research in Transportation Economics, vol. 17, pp. 517-566, 2007.

[44] W. Cook, Y. Roll, and A. Kazakov, "A DEA model for measuring the relative efficiencies of highway maintenance patrols," INFOR, vol. 28, no. 2, pp. 113-124, 1990.

[45] R. D. Banker and R. C. Morey, "Efficiency analysis for exogenously fixed inputs and outputs," European Journal of Operational Research, vol. 34, no. 4, pp. 513-521, 1986.

[46] J. Ruggiero, "Non-discretionary inputs in data envelopment analysis," European Journal of Operational Research, vol. 111, no. 3, pp. 461-469, 1998. 


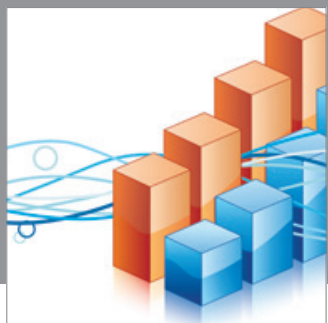

Advances in

Operations Research

mansans

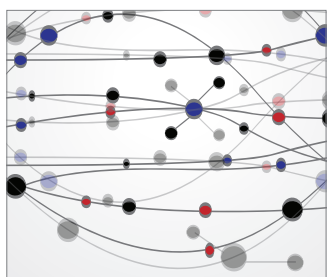

The Scientific World Journal
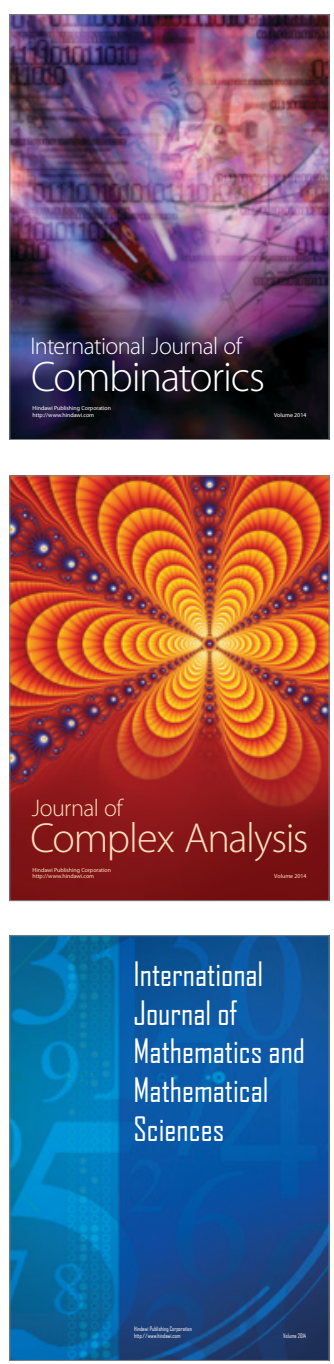
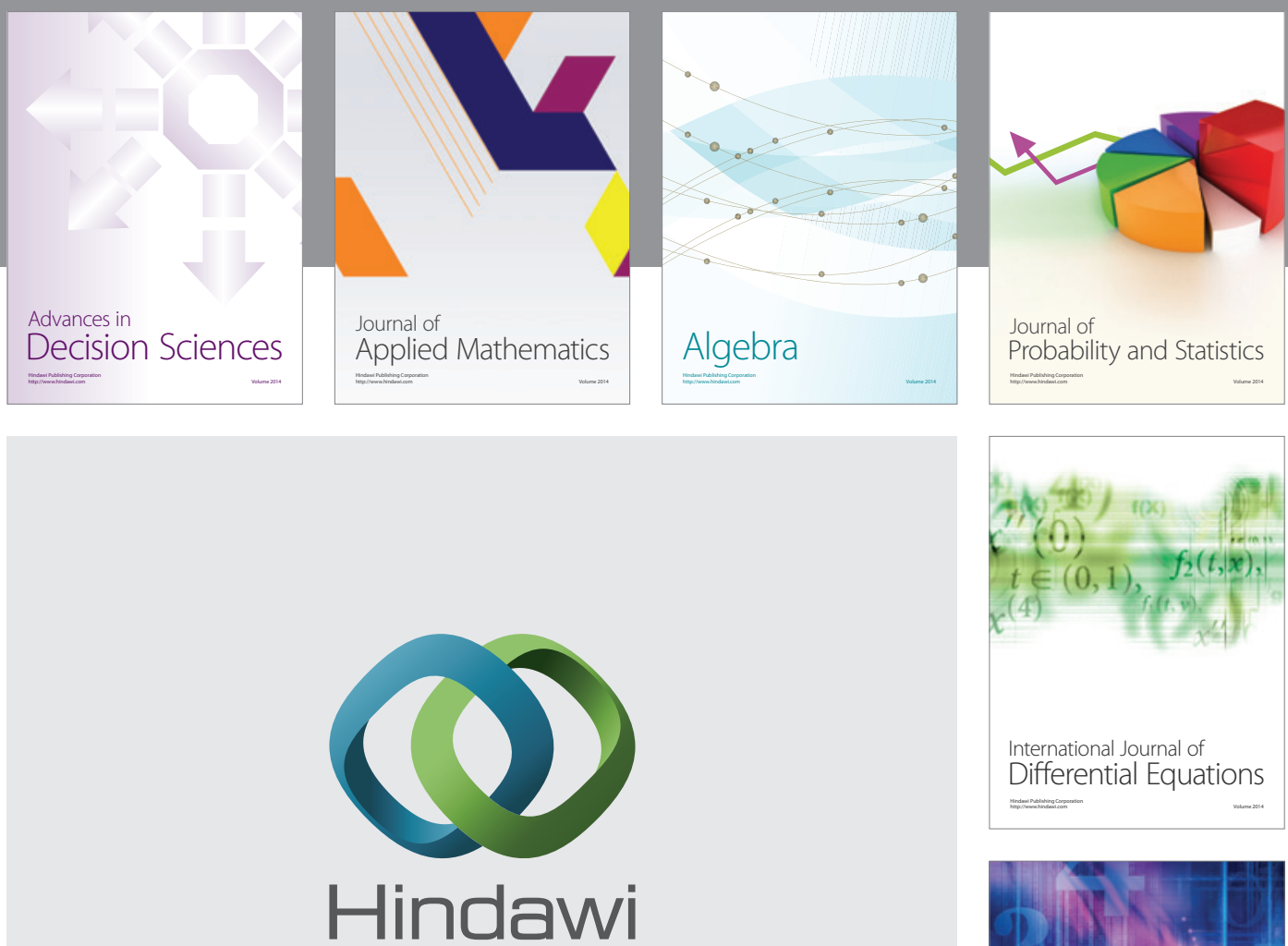

Submit your manuscripts at http://www.hindawi.com
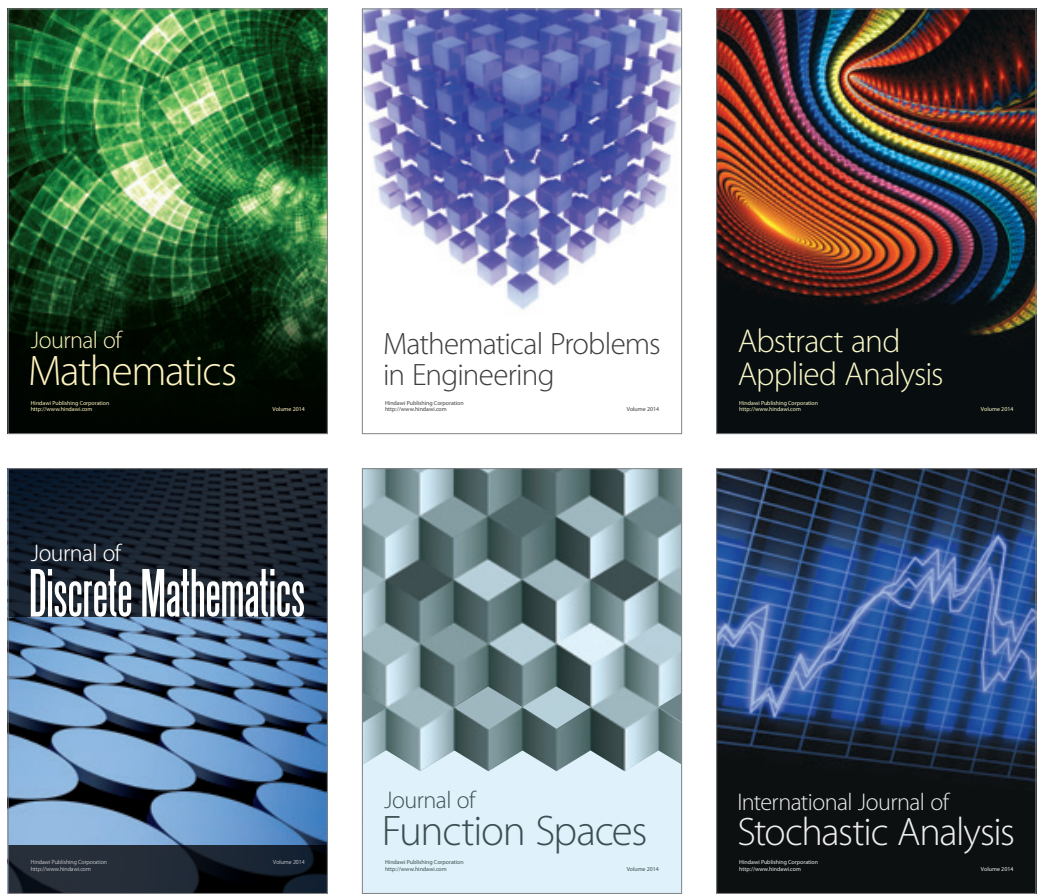

Journal of

Function Spaces

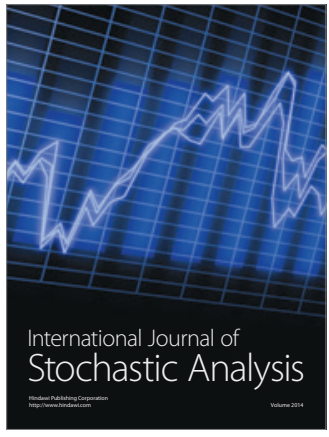

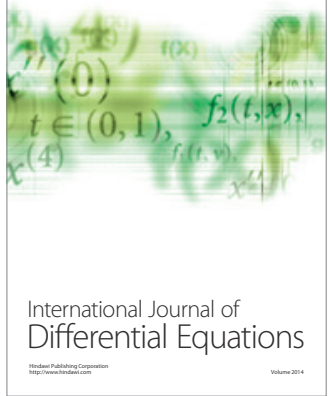
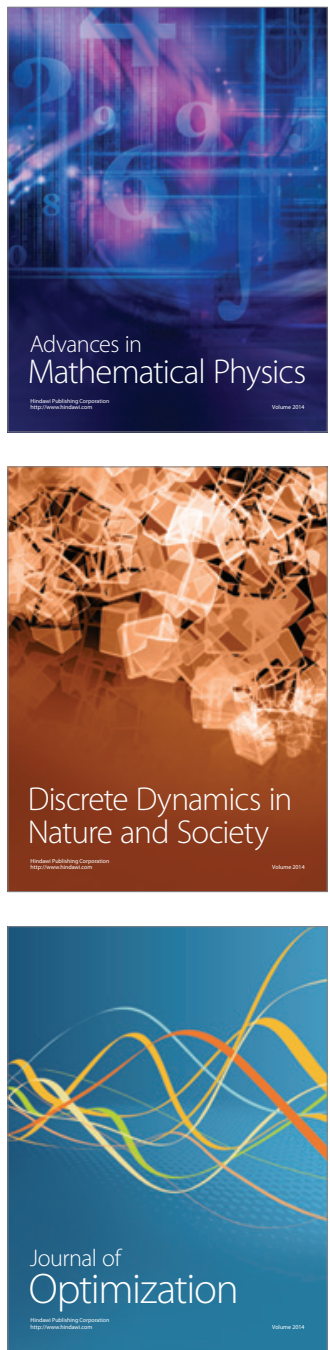